\title{
El incendio de Roma del año 64: Una nueva revisión crítica
}

\author{
Pilar fernández Uriel *
}

El año 64 d.C. fue en sí mismo un momento problemático: Atravesaba el principado de Nerón una etapa de inestabilidad interior. Era un año límite entre la llamada política senequista y el "Aula Neroniana". Al mismo tiempo, parecian vislumbrarse los primeros brotes de rebeldia a la imposición del neronismo, que, aun soterrados, aflorarian un año más tarde con la conjuración de Pisón '.

Sin embargo, el año 64 fue uno de los más sobresalientes y brillantes en la politica exterior neroniana, alcanzándose importantes logros como el total establecimiento romano en el Mar Negro, especialmente en el Ponto Polemonaico, la concesión de ciudadanía a la población de los Alpes marítimos o la definitiva relación comercial diplomática con la dinastía de Assum de la Etiopia meroitica. Los romanos pudieron utilizar el puerto de Assab y acceder al oro etiópico?

La expansión comercial romana quedó también reforzada al terminarse la ampliación de puerto de Ostia, iniciada por Claudio, y el puerto militar del lago Averno (Suetonio, Nero, 31).

* Departamento de Prehistoria e Historia Antigua. UNED.

- Posiblemente, las modificaciones en el regimen se realizarian entre los años 61 al 63. pero hasta el año 64, cuando se afirma el Aula Neroniana en el gobierno. Cfr. Cizek, E., L'Epoque de Neron et ses controverses ideologiques. Leiden, 1972, págs. 145 y ss.; Tambien Fernandez URIel. P., Aspectos socio-politicos de la época neroniana, Madrid. 1982, págs. 304 y ss.

Suetonio, Nero, 19; Aurelio Victor, De Caes., 5; Seneca, De Nat. Quaest., VI, 8-3; Plinio, Nat. Hist.. VI, 181, y XII, 19: DION CASSIO. LXIII. 8. Para el estudio de la política exterior de Nerón, referente a la parte oriental del Imperio, ver: SCHUR, W., "Die Orient politik des Kaisers Nero", Klio, Beihft, 15, Leipzig, 1923; Hammono, M., "Corbulo and Nero's Eastern Policy», Harvard. Stud. Class. Phild., 45, 1934, págs. 81-104. 
El 19 de julio de aquel mismo año, una gran catástrofe abatió la capital del Imperio. Tal catástrofe, por su propia configuración y, sobre todo, por las consecuencias que trajo consigo, ha sido un punto atrayente para los estudiosos del mundo romano.

Pese a ello, todavia hoy continúa como un acontecimiento histórico no esclarecido. Su estudio ofrece dificultades muy peculiares en parte debido a las propias fuentes históricas, pero también por las importantes y trascendentales cuestiones de orden ideológico, legislativo y social que plantea.

Aún se encuentran fuera de nuestro alcance las explicaciones de tales cuestiones, pero, al menos, intentemos poner al dia el análisis de estos hechos y recordar la ya vieja problemática del gran incendio del año 64 en Roma.

\section{EL INCENDIO}

Según las propias cuentas de los romanos, completadas por el famoso cálculo de Grotenfeld, recogido por Koestermann, pasados 418 años, 418 meses y 418 dias de la invasión de Roma por los galos, se producia otro gran desastre en la capital del Imperio, calificado por Tácito como "el más grave y atroz de cuantos se produjeron por la violencia del fuego" (Tácito, Ann., XV, 38, 1).

Son diversas las referencias que nos han llegado procedentes de los autores antiguos, pero su aportación, además de escasa, ofrece datos inciertos e, incluso, con frecuencia no existe concordancia entre los mismos en cuestiones tan principales como la causa del incendio, su duración o sus pérdidas ${ }^{3}$.

Al parecer, el incendio se produjo la noche entre el 18 y 19 de julio, en la parte sureste del circo Máximo, en las cercanías de la Puerta Capena, propagándose el fuego con extraordinaria rapidez, debido principalmente a tres factores, según se desprende de la narración de Tácito:

3 Las fuentes más completas que hacen referencia al mismo, son Tácito, Suetonio. Dión Cassio, el autor de la tragedia "Octavia" (Pseudo Séneca), S. Jerónimo, Eutropio y las cartas apocrifas entre S. Pablo y Séneca. Es importante el trabajo sobre estas fuentes realizado por HEINZ, K., “Das Bild Kaiser Neros bei Seneca, Tacitos, Sueton and Cassios Dio". Historish-Philologische Sypnosis, Berna, 1948 
- La enorme cantidad de material inflamable que el fuego encontró a su paso. Es de sobra conocida la ubicación de tenderetes y puestos callejeros situados en torno al circo y lugares de espectáculos públicos de Roma. Además, esta disposición al fuego era correspondida por la mala urbanización y construcción de las casas, formando calles estrechas y tortuosas: “... Allí, por las tiendas en las que había mercancias idóneas para alimentar el fuego, en un momento estalló y creció el incendio... No habia por medio casas protegidas por recintos resistentes, ni templos rodeados de muros, ni cosa alguna que pudiera representar un obstáculo" (Tácito, Ann., XV, 38, 2-4).

- Al parecer, el fuego fue también activado por un fuerte viento: "(el fuego) ... azuzado por el viento cubrió toda la longitud del circo" (Tácito, Ann., XV, 38, 4).

Los dos vientos que atacan con frecuencia las costas del mar Tirreno, al sur del Tiber, son el Sirocco (que sopla hacia el sur) y el Libecio (que sopla hacia el suroeste). La fuerza de estos vientos y su dirección concuerdan con las indicaciones dadas por Tácito sobre la expansión del incendio (Beaujou, J., 1960, 65-80).

El viento, que provenía del sur y suroeste, provocó la propagación del fuego hacia el norte y noroeste de la ciudad, extendiéndose por el Foro Boario, monte Celio, monte Palatino y via Triunfal, y de allí descendió al valle Mucio, hacia la colina Velia y hacia donde más tarde se asentaria el anfiteatro Flavio, el monte Fagutal y el monte Oppio.

- La precipitación de unos, la confusión de otros y el pánico y el terror de todos provocaron atascos y aglomeraciones, agravando con ello las situaciones de peligro y provocando nuevas desgracias al incendio: "Se añadía, además, los lamentos de las mujeres aterradas, la incapacidad de los viejos y la inexperiencia de los niños, y tanto los que se preocupaban por si mismos como los que lo hacian por otros arrastrando - guardando a los menos capaces, unos con su demora, otros con su precipitación, ocasionaban un atasco general» (Tácito, Ann., XV, 39, 4).

Tanto Suetonio como Tácito coinciden en que la duración de este incendio fue de siete noches y seis días. Dión Cassio no refiere un tiempo definido para el incendio (Tácito Ann., XV, 40, 1; Suetonio, Nero, $38,4)$.

Solamente Tácito narra una segunda parte del incendio, que duraria, tal vez, un par de días más que al parecer se declaró en el campo de Marte, en una propiedad de Sofonio Tigelino llamada Praedia Aemiliana, 
de dificil localización. Ello dio lugar a rumores de que este segundo incendio hubiera sido provocado (Tácito, Ann., XV, 40, 2).

Parece significativo que el resto de las fuentes ignoren este segundo incendio. Cabria la posibilidad que se tratara de los últimos vestigios del mismo aún sin dominar, y que, al igual que en el campo de Marte, quedaran algunos focos del desastre en otros puntos de Roma, por el Aventino o el Quirinal, tardando dos dias más en sofocar definitivamente el fuego. En total sumarían unos nueve dias.

En lo referente a las pérdidas, las fuentes literarias también se hayan divididas:

Según Tácito, de los 14 barrios en que se hallaba fragmentada la ciudad, sólo cuatro quedaron idemnes al fuego, tres fueron destruidos y los otros seis restantes presentaban vestigios del desastre (casas abatidas, saqueadas o parcialmente quemadas) (Tácito, Ann., XV, 40, 4) ${ }^{4}$.

Dión Casio presenta una versión más exagerada de las pérdidas, aumentando la destrucción de la ciudad en su dos terceras partes "donde la mayoría de las casas quedaron destruidas por el fuego y sólo alguna se pudo salvar" (Dión Cassio, LXII, 18, 1).

Suetonio no ofrece ninguna relación concreta de los daños producidos por el incendio, limitando éstos a cla destrucción de un gran número de casas particulares" (Suetonio, Nero, 38, 6).

También resulta difícil ofrecer una enumeración más detallada de los monumentos quemados y reducidos por el fuego. La mayoría de los mismos eran los templos más antiguos de Roma, consagrados en tiempos de los reyes o levantados tras las guerras púnicas o el saqueo de los galos senones. Hemos de recurrir de nuevo a Tácito por ser quien ofrece una descripción más detallada de los mismos. Menciona el historiador la pérdida del templo dedicado a Lucina, atribuido por la tradición al rey Servio Tulio; el gran altar y el templo dedicado a Hércules auxiliador por el mítico arcadio Evandro. En el norte del Palatino fue destruido el templo de Júpiter, cuya consagración se hacía remontar a Rómulo, también el palacio de Numa y el templo de Vesta con todos los Penates del pueblo romano. Añadia Tácito: "Las riquezas y trofeos ganados en tantas victo-

\footnotetext{
${ }^{4}$ Los barrios que quedaron libres del desatre fueron los extremos del Transtiberiano, V, oeste; Porta Capena. I, sureste; Esquilino, V, este, Via Lata (Alta Semita), VI, noroeste. Las partes más destruidas fueron las más céntricas y más pobres y desde donde, posiblemente, se propagó el fuego: Palatino, X; Circo Máximo, XI, y el barrio de Isis y Serapis, en el Oppio. III.
} 
rias y las bellezas del arte griego, los testimonios antiguos e intactos de los genios literarios, de manera que aun ante la belleza de la ciudad que resurgia, los viejos recordaban muchas cosas que ya no podrian recuperarse..." (Tácito, Ann., XV, 41, 2) ${ }^{5}$.

Dión Cassio añade otras pérdidas como el pequeño anfiteatro de Estatilio Tauro, situado en el campo de Marte (Dión Cassio, LVII, 18, 2) ${ }^{6}$.

Se podrian agregar otros edificios de los que conocemos su antigua existencia. Al encontrarse ubicados tradicionalmente en los barrios más dañados por el incendio, quedarian igualmente destruidos los antiguos foros, el templo de Apolo Palatino, el antiguo teatro Marcelo y el palacio de Tiberio.

Nerón hizo reconstruir algunos de estos monumentos como el circo Máximo y los templos de Apolo y Ceres en el Palatino. De otros, apenas quedan referencias. Sobre los restos del antiguo palacio de Tiberio se construyó la famosa Domus Aurea Neroniana, magnífica mansión que se extendía desde el Viminal y el sur del Esquilino hasta la ladera Celia (Tácito, Ann., XV, 42; Suetonio, Nero, 31) ${ }^{7}$.

Mucho más difícil de calcular son las pérdidas referentes a las casas particulares, construidas con materiales frágiles y fácilmente inflamables, formaban las calles tortuosas y estrechas de los barrios más antiguos y

${ }^{5}$ Koesterman, E., 1971, 634, siguiendo el códice "Leidensis" (frente al "Lunae del Mediceus" que prefieren otros autores), piensa que el templo dedicado a Lucina, citado por Tácito, se refiere al templo de Diana en el Aventino, advocada con este nombre y atribuido por la tradición al rey Servio Tulio. Ver también HOMMEL, H., "Tacitus und die Christen", Theologia Viatorum, 3, 1951, págs. 10-30. El pequeño "Fanum" de Hércules se encontraba al suroeste del Palatino; el templo de Júpiter Estátor (Stator = el que detiene) se ubicaba al norte del Palatino, en la zona que luego se alzaría el arco de Tito. Según la tradición, procedía de una ofrenda de Rómulo a Júpiter por su ayuda en su lucha contra los sabinos. Los estudios posteriores han demostrado que este templo se levantó en el 294 a.C.; la "Regia Numae", sede oficial del "Pontifex Maximus", y el templo de Vesta se encontraban en el Foro Romano.

${ }^{6}$ Es dudoso el emplazamiento de este pequeño teatro. Ha sido estudiado por LuGLi, E., I Munumenti Antichi di Roma e Suburbio, t. III, Roma, 1938, pág. 458. Recogido por BeAujou, J., obra citada, pág. 66. Ello confirmaría la alusión de Tácito referente al segundo incendio en el campo de Marte y su posible origen en la Praedia Aemiliana, propiedad de S. Tigellino.

7 Sobre la Domus Aurea Neroniana ver entre otros: PRECHAT, M. F., "Sèneque et la Maison d'Or", Revue de l'Acad. des Inscriptions et Belles Lettres, 1914, págs. 231-234; Boethius, A., The Golden house of Nero, Londres, 1961; Griffin, M., Nero: The end of a Dinasty, Londres, 1987, pág. 130; Grant, M., Nero, Londres, 1970, págs. 170 y ss. Para Grant, la Domus Aurea ocuparía desde el Quirinal a la ladera Celia y desde el monte Esquilino hasta el Foro, en total tendría una superficie de unos 125 a 320 acres. 
populosos de Roma que, evidentemente, fueron los más perjudicados por el desatre: el del circo Máximo, la Subura y el Palatino.

Ninguno de los principales autores clásicos se atrevió a ofrecer detalle alguno sobre las pérdidas de este tipo. Sólo la carta apócrifa entre Séneca y San Pablo se aventura a dar una relación de cifras. Indica que fueron 132 Domus (casas particulares) y 4.000 Insulae (inmuebles de varias viviendas) las destruidas en el incendio, pero los estudiosos de este documento no dan demasiada credibilidad al mismo ${ }^{8}$.

\section{LAS CAUSAS}

Posiblemente, la cuestión más dificil y problemática que se plantea al historiador sea la causa de la aparición y la propagación del incendio.

Se han expuesto varias causas posibles que pudieran reducirse, fundamentalmente, a cuatro.

\section{1. ${ }^{a}$ Por accidente fortuito}

La mayor parte de los historiadores actuales que han analizado el problema del incendio del año 64 coinciden en aceptar que éste se desataría por azar, a causa del calor, la sequedad del ambiente, la mala disposición de las tiendas y las viviendas, el desorden en las calles y las casas, la mala construcción de las mismas, etc. Ayudó a su propagación condicionantes naturales, como el viento, y humanas, como el lógico terror y desconcierto de las gentes afectadas en el mismo, como parecen indicar las propias fuentes ${ }^{9}$.

Por ello, la tendencia actual es no atribuir ningún autor concreto, ni comunidad ni agrupación ideológica alguna como responsables directos de tal incendio. Por el contrario, muy posiblemente el mismo tendría un

${ }^{8}$ Centum triginta duae domus, insulae quatuor milia sex diabus arsere. Posiblemente estas cifras pertenecieran al siglo iv. La diferencia entre Insulae y Domus sería prueba de ello. Los cálculos serian trastocados de una fuente anterior.

${ }^{9}$ Radius, E., L'Incendio di Roma, Milán, 1962; Beaujou, J., obra citada, pág. 80. También HOHL, E., "Domitius (Nero)", en Real Encyclopadie, Supl. t. II. núm. 29, pág. 381; Cizek, E., obra citada, pág. 164; LEVI, M. A., Nerone e suoi tempi, Milán, 1972. 
origen tan casual como otros anteriores que sufrió Roma, aunque éstos no tuvieran las dimensiones catastróficas ni la reacción popular ni las consecuencias sociales y políticas en las que se vio envuelto el propio principado neroniano. Esta última observación debe ser considerada como un dato muy significativo que los estudiosos del tema no han tenido suficientemente en cuenta.

Es muy posible que la magnitud de las pérdidas humanas y materiales fueran el motivo más importante de esta reacción popular, pero ésta encontró un momento socio-político favorable dada la situación crítica y conflictiva que atravesaba el principado. El descontento político y la inestabilidad interior serian un poderoso factor que alimentara las exigencias populares de encontrar unos posibles autores sobre los que recayera la responsabilidad del incendio y descargar sobre ellos la indignación y el descontento de las víctimas. Por ello las fuentes literarias nos remiten a posibles causantes del mismo.

\section{2. $\quad$ Por orden de Nerón}

Casi todas las fuentes históricas responsabilizan del hecho al último Julio-Claudio y sobre él hacen recaer esta acusación: Originó el incendio para conseguir un doble propósito:

- Provocó el incendio para destruir la ciudad y sobre sus cenizas reconstruir una nueva Roma a su gusto, dándole su propio nombre $\mathrm{Ne}$ ronia, en la que se levantaria un nuevo palacio imperial muy superior al de sus antecesores, al estilo de los príncipes helenísticos.

- El segundo propósito parece más que una acusación una censura ante la postura del Princeps durante el incendio: Nerón se había dedicado a contemplar tan dantesco espectáculo desde la torre de Mecenas, aprovechando el singular decorado para cantar el poema compuesto por él mismo, Toiae Halosis, dedicado a la caida del llión, "Comparando las desgracias presentes con los antiguos desastres" (Suetonio, Nero, $38,13)^{10}$.

${ }^{10}$ Hoc incendium e turi Maecenatiana prospectans laetusque flamma, ut aiebat, pulchretudine, Halosis Ilii in illo scenico habitu decantiavit, TACITO, Ann., XV, 39, 4; También DioN CASsio, LXII, 16-1; Eutropio, Brev. Vit., 7, 9. Ver PICARD, CH., Auguste et Nero. Le secret de l'Empire, Paris, 1962, pág. 157. 
Cabe la posibilidad que esta segunda acusación sea cierta, por lo que se adecúa al espíritu inquieto, turbulento y exageradamente preocupado por las manifestaciones artísticas de Nerón. Tal vez, atraido por la inigualable escenografía que el incendio le brindaba, se sintió atraido a vivir la experiencia apocalíptica de los héroes troyanos y a cantar tales vivencias en aquel singular escenario "encantado por la hermosura de la llama" (Suetonio, Nero, 38, 13).

Cantara o no el propio Nerón la toma de Troya ante las llamas de Roma es algo puramente secundario y anecdótico ante la acusación principal de provocar él mismo el incendio, culpa que le imputan casi todos los autores antiguos.

Plinio el Viejo, Suetonio y Dión Cassio acusan clarísimamente a Nerón. Los autores posteriores, Eutropio y San Jerónimo, basándose en los primeros, también le condenan en términos semejantes ${ }^{11}$.

Sólo dos autores de la época no culpan abiertamente a Nerón:

El autor de la tragedia Octavia (Pseudo-Séneca, w, 831-833), donde supone a Nerón como cómplice del hecho, sin afirmar ni desmentir nada.

También Tácito (Ann., XIII, 20, 2-3, y XV, 39, 1-3), quizá la principal fuente de la historia neroniana, rehúsa emitir un juicio claro respecto a la autoría del incendio, dejando al lector la alternativa de elegir entre accidente o crimen. Es posible que de los tres autores que Tácito consultó en la realización de su obra, Plinio el Viejo, Fabio Rústico y Cluvio Rufo, tomara básicamente el testimonio de este último, que de los tres aportaba una crítica más objetiva y menos hostil al príncipe (SYME, R., 1958, 287).

La mayor prueba de acusación que presenta Tácito es la relacionada con el rumor extendido por Roma de que el incendio fuera reavivado por orden de Nerón en un lugar aparentemente sospechoso como es la llamada Praedia Aemiliana, propiedad del prefecto del pretorio, el poderoso Sofonio Tigelino.

La narración de Tácito (Ann., XV, 40,3) parece aprobar esta acusación, sin atreverse a confirmarla objetivamente. Hermann Schiller piensa

"También: Dión Cassio, XLII, 16, 2; Plinio, Nat. Hist., XVII, 1, 5; Eutropio, Brev. Vit., 79; San Jeronimo, Chron., pág. 183. No parece convincente la tesis de Cizek, E. (obra citada, pág. 190) en que haya diversas opiniones entre los autores de la época. E. Cizek se basa en el juicio poco claro de Tácito y en la ausencia de acusaciones directas por parte de Flavio Josefo y de Marcial, que siempre fueron hostiles a Nerón. 
que el autor se limita a sugerir al lector la hipótesis de culpabilidad de Nerón al no encontrar pruebas claras de ello (SCHILLER, H., 1872) ${ }^{12}$.

La historiografía moderna casi en su totalidad es, en cambio, partidaria de la inocencia del príncipe, coincidiendo en aceptar la accidentalidad del incendio ${ }^{13}$.

La gran preocupación de Nerón ante la catástrofe y el paquete de medidas que se tomaron tras producirse la misma, posiblemente sea una de las pruebas principales de su no intervención en el origen del fuego: Para albergar a la multitud perjudicada en el incendio se abrieron al pueblo el campo de Marte, los monumentos de Agripa y los propios jardines imperiales, donde se levantaron construcciones improvisadas para cobijarles de la intemperie. Tras estos primeros auxilios, se realizaron expiaciones a los dioses y súplicas a Vulcano.

Posteriormente se tomaron otras medidas de mayor envergadura: Se mandó bajar el precio del trigo y traer víveres desde Ostia a pesar del gran detrimento que ello suponía para la economia romana, procediendo a continuación a la reconstrucción de la nueva Roma ${ }^{14}$.

\section{3. $\quad$ Por los miembros de la conjuración pisoniana}

Una segunda acusación de culpabilidad de provocar el famoso incendio es atribuida a los miembros de la conjuración de Pisón, sofocada un año después. El defensor de esta tesis es U. de Franco (De Franco, U., 1946 y 1956).

${ }_{12}$ Plusque infamiae id incendium habuit quia praedis Tigellini Aemilianis proruperat videbaturque Nero condendae urbis novae et cognomento suo apellandae gloriam quaerere. (Tacito, Ann, XV, 40, 3).

${ }^{13}$ Allard, P., Les chrétiens ont-ils incendie Rome sous Néron, Paris, 1904: Ibidem. "L'incendie de Rome et les premiers chrétiens", Rev. catht. des institutions et du droit, 35 , 1905, págs. 103-122 y 246-253; Beaujou, J., obra citada, págs. 60 y ss.; Clarton, F. W., "Tacitus and Nero's Persecution of the Christians", Clasical Quaterly, 41, 1947, págs. 8185; También CIzEK, E.; obra citada, pág. 190; LEVI, M. A., obra citada, pág. 203; PARATORE, E., "Nerone (nel XIX centenario della morte)", Studi Romani, XVIII, 1969, págs. 272-287; PICARD, CH., obra citada, pág. 157; Questa, C., Studi sulle fonti degli Annales de Tacito, Roma, 1960, págs. 161-166.

${ }^{14}$ A través de los testimonios de Tácito conocemos las medidas tomadas por Nerón (Tácito, Ann., XV, 39, 1-4). Se abrieron los campos de Marte, el monumento de Agripa e, incluso, sus propios jardines, construyéndose barracas para albergar a la multitud, frente a la afirmación de Suetonio que "el pueblo no tuvo otro lugar donde cobijarse que en los monumentos y en los templos" (SUETONIO, Nero, 38). 
U. de Franco se basa en la posibilidad de que este grupo de conjurados, descubiertos en la primavera del año 65, estuvieran ya organizados en el verano anterior e incluso trabajando para boicotear la política del Aula Neroniana.

Por otra parte, el desorden y la confusión provocados por el incendio invitaba a ser una excelente ocasión para la conspiración y, tal vez, dar muerte al césar, como sugiere Tácito. Además, el incendio resultaria el medio más idóneo para avivar el descontento popular y provocar un nuevo conflicto social en Roma, propagando entre el pueblo la culpabilidad de Nerón en el hecho ${ }^{15}$.

La hipótesis presentada por $U$. de Franco no ha tenido aceptación entre los historiadores que ponen como principal objeción a su posibilidad histórica el que ninguna fuente presente algún dato fiable en que se pueda basar esta teoria.

Simplemente se inclinan a considerar que el incendio hubiera sido aprovechado eficazmente por los enemigos del neronismo para propagar una publicidad negativa y el descontento al régimen impuesto.

Realmente, la popularidad de Nerón y de su régimen disminuyó considerablemerte, no sólo ante la catástrofe, sino por el déficit económico que suponía las enormes pérdidas y sus secuelas: la carestía de lo más necesario, la falta de viveres y de alojamiento para aquellos que perdieron sus bienes en el incendio, quedando sin lo más indispensable.

\section{Por la primera comunidad cristiana de Roma}

También resulta conflictiva la posible culpabilidad de otros terceros: los primeros cristianos de Roma.

Esta cuarta posibilidad está llena de problemas e interrogantes para el historiador: la primera, la difícil cuestión de su origen e identidad, quiénes eran los primeros componentes de la Iglesia primitiva de Roma.

${ }^{15}$ Uno de los conjurados pisonianos, Subrio Flavio, intentó matar a Nerón mientras ardía la Domus Transitoria (TACITO, Ann., XV, 50, 5). Además era un momento social y politico bastante conflictivo: Se habian producido ciertas manifestaciones populares contra la ejecución de la Familia de L. Pedanio Secundo, prefecto de la ciudad, asesinado, y otros disturbios tras la caída de la emperatriz Octavia. 
Las opiniones de sus estudiosos suelen coincidir en que esta comunidad hizo su aparición en Roma entre los principados de Caligula y Claudio, siendo judíos la mayoría de sus componentes, aunque, desde fecha muy temprana, se añadirian a éstos ciertos adeptos procedentes de otras creencias, principalmente orientales, como puede deducirse de las epístolas de Pedro y Pablo (Meeks, W. A., 1985).

Apenas tenemos testimonios válidos que no informen convenientemente de esta primitiva comunidad cristiana. La escasisima información que disponemos prácticamente se limita a las fuentes cristianas, principalmente paulinas. Las introducciones de salutación de las epistolas son una valiosa información sobre las personas y grupos de esta comunidad. Aunque algunos pudieron pertenecer a familias acomodadas 0 , incluso, ocupar cargos de cierto prestigio, por lo general el "status" social de estos cristianos debió de ser muy bajo. Fueron en su mayoría esclavos, libertos, peregrini y también hombres libres que ejercian humildes oficios $y$, por tanto, sus posibilidades económicas y sociales serian muy limitadas. Todos ellos buscaron en el cristianismo un ideal de salvación y esperanza, al menos en el nivel espiritual (Sampley, J. P., 1988) ${ }^{16}$.

Tampoco conocemos los primeros pasos del cristianismo en Roma y cómo se desarrollaría éste hasta la época de Nerón. Parece muy probable que se iniciara en un ambiente prácticamente judio en el cual se detectaran ciertos rasgos orientales, por lo que la comunidad cristiana sería considerada en Roma como una secta judaica, o una superstitio más de las ya existentes, de tipo orgiástico oriental.

En todo caso, ya en el año 57 la comunidad cristiana de Roma estaba constituida y manifestaba cierta vitalidad. Pablo le dedica su Epistola a los romanos e incluso les envia a la diaconisa de la lglesia de la ciudad portuaria de Cencres, Febe, "Que me preside". Sus salutaciones parecen indicar un conocimiento y una relación con los miembros de la comunidad romana (S. Pablo, Epistola a los romanos, 16, 1-17).

Dos años más tarde, a finales del 59 , Pablo es enviado a Roma para ser juzgado por el propio César. Es dudoso el tiempo que pasó arrestado

${ }^{16}$ Sobre la posibilidad de la existencia de cristianos en la "Nobilitas" romana se encuentra el testimonio de Tácito (Ann., XIII, 32, 2-3): “Pomponia Graecina, patricia romana, fue acusada de practicar una superstición extranjera no licita. El Senado encargó a su marido de juzgarla según el Mos Antiquus, y éste declaró su inocencia. Tal ilustre dama vivió apartada del mundo y fue alabada por su virtud y recato". Este dato ha hecho pensar tradicionalmente que Pomponia Graecina fuera una de las primeras cristianas pertenecientes a la clase alta de Roma. (31) S. Pablo, Epist. a los romanos, 16, 1-7. 

y también la fecha en que fue juzgado, condenado a muerte $y$
ejecutado ${ }^{17}$.

$\mathrm{Si}$ es difícil conocer la realidad de los primeros cristianos de Roma, la dificultad se agrava al analizar sus posibles implicaciones en el incendio del año 64 .

Ningún autor antiguo, excepto Tácito y también Sulpicio Severo (Chron., II, 29), que se basa fundamentalmente en el famoso relato de Tácito (Ann., XV, 44), relaciona la condena de los cristianos con el incendio de Roma.

Este texto ha sido siempre objeto de estudios y controversias apasionadas al presentar una oscura y de difícil interpretación, en gran parte debido a la construcción de su sintaxis. Tales dificultades han sido planteadas en diversas hipótesis. Ya a comienzos de siglo, A. Profumo proponía una solución que incluso en la actualidad sigue encontrándose sugestiva y con indudables aciertos: Tal vez el relato referente a la comunidad cristiana fuera una interpolación realizada en el siglo Iv d.C. (Profumo, A., 1905) ${ }^{18}$.

${ }^{17}$ Las estancias de S. Pablo y S. Pedro en Roma son aceptadas históricamente. En cuanto la ejecución de ambos, al parecer, no se realizaron en la misma fecha. Es posible que $S$. Pedro fuera ejecutado antes, entre los años 62 y 63 , muriendo $S$. Pablo en el año 67. Griffe, E., Les persécutions contre les chrétiens aux ler. et ller. siècles, París, 1967; LECLERCO, J., L'Eglise des premiers siècles et les persécutions, Lieja, 1941.

${ }^{18}$ El pasaje de Tácito, que menciona a Cristo y a los cristianos, ha sido objeto de numerosos estudios y controversias, debido no sólo a la trascendencia de los mismos sino a la autoridad que merece Tácito como fuente histórica. Por ello el texto presenta indudables cuestiones de muy dificil aclaración:

- La tradición manuscrita da la lectura de "Chrestianos" y no "Christianos", lo que parece dar a entender que Tácito recogería su información de Suetonio, referida a un griego convertido al judaismo que provocaba disturbios en Roma (Claud., 25, 4). Cfr. BRUCE, F. F., "Christianity under Claudius", Bull. of the John Ryl. Libr., 44, 1961-62, págs. 309-326. Podria existir la posibilidad de que el "Chrestus", citado por Suetonio, se refiriera realmente a Cristo y que el nombre se debiera a un proceso de etimología popular, interpretándose no como "el ungido", sino como "el beneficioso", lo que ya resultaría difícil con una pronunciación "itacista" de la eta griega, pero a esta dificultad se le añade la incoherencia de que el nombre de "Christus", se encuentre documentado al lado del de "Chrestianos", Io cual resulta bastante ilógico y confuso.

- Poncio Pilato desempeñaba el cargo de "Procurator" en el dudoso pasaje de Tácito. El hallazgo epigráfico encontrado en 1961 en el antiguo teatro de Cesarea, publicado en L'Année Epigraphique, 1963, núm. 104, y 1971, núm. 477, indica que fue «Praefectus» de Judea entre los años 27 y 37 . Resulta difícil aceptar que un autor tan documentado como Tácito no conociera con exactitud el cargo de este personaje.

- No nos es posible saber si Tácito hacia mención de la muerte de Cristo en el lugar cronológico correspondiente de la obra, pues ésta perteneceria a la parte perdida del $\mathrm{Li}$ bro $\mathrm{V}$.

- Finalmente, el párrało, además de ser calificado por los estudiosos de "una crono- 
Un autor posterior como es san Jerónimo tampoco establece relación alguna entre el incendio de Roma, que coloca en el año 65, y la persecución de los cristianos, fechada por él en el año 68. Es posible que san Jerónimo recogiera las antiguas versiones de ambos hechos, no existiendo relación alguna entre ellas.

J. Beaujou explica la falta de conexión entre ambos acontecimientos por existir un intervalo demasiado largo de tiempo entre el incendio y la persecución de los cristianos, debido, quizá, a que el gobierno de Nerón tomara otras medidas más urgentes como las de tipo económico o de carácter social y religioso. Ello exigiría un periodo de tiempo relativamente largo al que hay que añadir el plazo comprendido entre la persecuación y el de los procesos y ejecuciones (Beaujou, J., 1960). Referente a esta cuestión, E. Koestermann ha llegado a calificar la persecución neroniana contra los cristianos de "falsa noticia", derivada de una errónea permutación de los textos de Tácito entre los seguidores y la nueva religión y una secta hebraica de distintos caracteres (Koestermann, E., 1967, 45).

Tampoco los testimonios literarios antiguos acusaron concreta y formalmente a la comunidad cristiana. Tácito expresa que fueron arrestadados (Primum correpti qui fatebantur: Se arrestó a quienes confesaban. ¿Pero de qué delito?) Lo cual no expresa cuál era realmente la culpabilidad. Por otra parte, la frase Ergo, abolendo rumori, subdidit reos. En principio, la palabra reos no significa culpable, sino, acusado. Sin embargo, esta frase es, sin duda, la que más podría relacionar, en su caso, el incendio de Roma y la inculpación a la comunidad cristiana.

A pesar de la fragilidad de esta y otras pruebas existentes hay una tendencia, defendida por algunos historiadores, que sugieren la posible autoría o, al menos, la participación real de los cristianos en el incendio.

Esta tesis fue lanzada por M. Pascal, aceptada por P. Bonifante y encontró su mejor defensor en L. Hermann, quien realmente desarrolló y divulgó la teoría (Pascal, M., 1901; Bonifante, P., 1923; Hermann, L., 1949).

logia relativamente precoz" en conjunto, presenta ciertos anacronismos como considerar a la comunidad cristiana de una multitudo ingens, cuando ésta, en sus inicios, tuvo que ser reducida $\mathrm{e}$, incluso, confundida a menudo con la judia o con otras superstitiones. Cfr. Koestermann, E., obra citada. Sobre la relación con la comunidad judia, Russell, A. G., "The jews, the Empire Romain and Christianity", Greece and Rome, 6, 1937, pags. 170178. 
Leo Hermann apoya su tesis en la creencia de una comunidad cristiana con una estructura organizada e, incluso, relativamente fuerte, to cual no es posible en Roma en una fecha tan temprana. Menos admisible es aún que personajes tan poderosos e influyentes en Roma como A. Burro, L. A. Séneca o R. Plauto fueran cristianófilos. Ello constituye un tremendo anacronismo cuando la comunidad cristiana era reducida y confundida con la hebraica.

Califica L. Hermann esta comunidad de inconformista y provocadora de diversos disturbios populares, siendo responsable de los conflictos sociales que sucedieron en aquellos tiempos. Es inadmisible que esta comunidad, pobre y mal vista públicamente, pudiera agitar de tal manera a la plebe de Roma ${ }^{19}$.

Atribuye, además, L. Hermann a los cristianos una tentativa de incendio en Roma en el año 57, un segundo incendio en Ludgunum, que al parecer ocurrió en el invierno del 64 , y el gran incendio de la capital del Imperio.

Apoya tan singular teoria en una doble prueba:

- La frase de Tertuliano: Una nox fuit inter urbem maximam et nuIlam (Apocaliptica, XXXVIII). Esta frase parece invocar una anterior de Séneca en su Carta a Lucilio, 91, dedicada al incendio de Lión: "Tantos edificios hermosísimos, cada uno de los cuales pudieran ser gala y decoro de una ciudad, los derrocó en una sola noche y en el seno de tan grande paz aconteció lo que ni aún en la más furiosa guerra pudiera temerse".

- En el año 67 se produjeron importantes disturbios en el seno de la comunidad judia de Antioquía a que conmovieron toda la ciudad y provocaron graves hostilidades contra la misma. Según narra Flavio Josefo, éstas fueron iniciadas por un "judio apóstata» que incitó a un pogrom contra su propio pueblo, al denunciar un complot para incendiar la ciudad, incendio que se produjo tres años más tarde, en torno al año 70. Resultó muy difícil demostrar la inocencia de la comunidad hebraica y

${ }_{19}$ Parece más coherente la posibilidad que estos disturbios populares se debieran únicamente a movimientos de carácter social, con causas y características propias, y no a motivos religiosos, independientemente de que pudieran participar en los mismos prosélitos cristianos. La fecha que indica $L$. Hermann para tales disturbios, tampoco parecen las más probables. El incendio de Lión, al parecer, ocurrió en el invierno del 64. Asimismo, la muerte de $\mathrm{S}$. Pedro y $\mathrm{S}$. Pablo no sucedería en torno al año 58 , sino entre los años 63 al 67 . 
calmar la animosidad de los antioquenos contra los judíos. Los antioquenos llegaron a pedir al emperador Tito la expuisión de los judíos, o, al menos, la reducción de sus privilegios, a lo que el césar no accedió (Flavio Josefo, Ant. lud., XII, 120).

A pesar de la inquietante coincidencia de disturbios y catástrofes en ciudades donde se ha detectado actividad por parte de comunidades cristianas en un intervalo cronológico relativamente reducido, sólo se ha considerado aceptable la reflexión sobre la posibilidad que una comunidad incipiente como la cristiana viviera momentos de exaltación en la fecha que daba sus primeros pasos, aprendía sus doctrinas e, incluso, recibia la visita de sus dirigentes, Pedro y Pablo. Exaltación que podría, tal vez, haber alcanzado ciertos grados de fanatismo entre algunos de sus miembros, acusando a Roma de "nueva Sodoma", ante el espectáculo del fuego, y condenando a la ciudad de acabar como la legendaria ciudad bíblica.

Menos verosimil nos parece su pública participación en el incendio, aunque autores como J. Beaoujou y E. Paratore admiten la posibilidad de que ciertos prosélitos cristianos estuvieran en los grupos que según el relato de Tácito y Suetonio: "servidores de la casa imperial, con estopas y antorchas en la mano, avivaban al fuego y se dedicaban al saqueo sin que nadie se atreviera a detenerlos... alegando que les estaba permitido". Se conoce la existencia de cristianos en la casa del príncipe, eran antiguos servidores de Narciso que pasaron a Nerón en el año 55 (Beaujou, J., 1960; Paratore, E., 1969).

Tal vez, según estos autores, entre las gentes que aprovecharon la confusión y se dedicaron al saqueo, propagando con sus actividades el incendio, se encontraran algunos cristianos que, llevados por su fanatismo, decidieran participar en el incendio considerando este «fuego apocalíptico" como castigo divino enviado a la ciudad e incluso expusieran su ánimo públicamente ${ }^{20}$.

${ }^{20}$ Recogido de Apocalip. 1, 8; XIII, 2, y XXVI, 6; SUETONIO, Nero, 38; TACITO, Ann., XV. 39,8; DION CASSIO, XLII, 17, 1. Es posible que a las indudables motivaciones religiosas se añadieran las ideológicas y políticas. Los judios provenientes de Jerusalén portaban la ancestral aversión judia hacia Roma, que consideraban, no sin falta de razón, como el enemigo implacable. Sin embargo, los judios de Roma, como los de las principales ciudades del Imperio, adaptados a su medio social e ideológico, como indican los textos de F. Josefo y Filón, consideraban a Roma como su protectora. Este motivo, pues, se añadiría a las causas religiosas, al posible fanatismo cristiano y al entrentamiento entre la comunidad judia y la cristiana. Cfr. MEEKS, W. A., obra citada, pág. 93. 
En este punto hemos de volver al oscuro relato de Tácito, en el que parece deducirse que los cristianos pagaron como víctimas para acallar los rumores que amenazaban al propio césar, remitiéndonos a los ambiguos términos Et abolendo rumores... subdidit reos.

Ante el análisis de estos párrafos surgen una serie de cuestiones: ¿Los cristianos acusados de participar en el incendio confesaron su culpa? Por otra parte, no parece verosimil, como ya expusieron Clayton y De Sainte Croix, que se obligara a inocentes a confesarse culpables, ni que la sociedad romana aceptara de tan buen grado y tan prontamente unos falsos incendiarios, por lo que se abre la interrogante hasta dónde los cristianos fueron realmente víctimas de la política imperial (Clayton, $F$. W., 1947, 81-85; De Sainte Croix, G. E. M., 1963, 6-38).

Sin embargo, la propia frase original de Tácito Subdidit reos... indica solamente que se provocó su acusación, sin que encontremos especificación de la misma, por lo que no podemos descartar la posibilidad de que las acusaciones y procesos recaidas sobre los cristianos no tuvieran que ver con el incendio de Roma y que fueran sacrificados por motivos de "utilidad pública».

Los enormes prejuicios sociales e ideológicos existentes hacia los cristianos facilitarian la labor del gobierno. Era una comunidad compuesta principalmente por gentes de origen sirio-palestino. Su conducta era tildada de rebelde y practicaban una religión calificada por el propio Suetonio como Nova et malefica superstitio, y por Tácito, Exitiabilis superstitio (Lepelley, C., 1969, 12; Theissen, G., 1985, 60).

Basándose en la frase de Tácito, Quam odio humani generis convicti sunt, se ha considerado tradicionalmente que la opinión popular acusaba a los cristianos de seguir una secta de carácter orgiástico cuyas prácticas y rituales "mágicos" exigían horribles delitos (canibalismo mágico o "comida de Thyeste" y "banquetes Oedipeos", incesto, estupro, infanticidio o “muertes rituales"...) (Nestle, W., 1927, 91). Sin descartar tal opinión, podria incluirse la lógica y acertada la hipótesis de otros estudiosos del tema como E. Zeller, J. Beaujou, H. Fuchs y R. Freundenberger que consideran que tal frase se refiriera a una idea de misantropia por parte de la comunidad cristiana, en el sentido usado por la terminología ciceroniana, como una comunidad de gentes separadas del resto de la sociedad y con el deseo de incomunicación con la misma. Quizá este alejamiento fuera uno de los principales motivos de su desconocimiento real y de ser considerados como individuos peligrosos y sus prácticas abominables. Prueba de esto es la extraordinaria concordancia entre los 
autores antiguos, Tácito, Suetonio y Plinio el Joven, en sus calificaciones y descripción de la comunidad cristiana ${ }^{21}$.

La historiografía más tardía también cita las acusaciones de las que fueron victimas los cristianos: Infanticidio e incesto es citado por S. Justino y otros apologistas griegos.

Por su parte, Tertuliano y Arthenágoras dicen que «los cristianos son perseguidos a causa de su fe» (Athenágoras, Leg., I, 2; Tertuliano, Apo$\log , 4,3)$.

La famosa frase de Tertuliano: Non licet esse christianos, y su expresión del término Institutum Neronianum, ha hecho considerar que desde Nerón el sólo hecho de ser cristiano se condenó como un delito suficientemente grave como para justificar una ley explícita para su condena y proceso (Tertuliano, Ad. Nat., I, 7) ${ }^{22}$.

J. Zeiller ha sido posiblemente el mejor defensor de la autenticidad histórica del llamado Institutum Neronianum, al que le considera un edicto imperial, origen de la legislación que avalaba juridicamente la persecución y castigo a los cristianos, permaneciendo en vigor a lo largo del Alto Imperio.

El término Institutum Neronianum es, para J. Zeiller, un término correcto en sus caracteres históricos y legales, no sólo testimoniado en la obra de Tertuliano, sino otros textos paganos (como la famosas carta de Plinio el Joven a Trajano) y en la literatura cristiana posterior (Zeiller, L., 1956, 1946 y 1951).

Sin embargo, como ya expusieron autores como Ch. Saumagne y J. W. Borleffs, tanto las fuentes paganas como cristianas parecen indicar

21 Suetonio, Nero, 16; Tacito, Ann., XV, 44; Plinio, Epist,, X, 96. Babut, E. C. H., "Remarques sur les deux lettres de Pline et de Trajan relatives aux chrétiens de Bithynie", Rev. Hist. lit. rel., n. s. 1. 1910, págs. 84-108; ZELLER, E., “Das odium humani generis der Christen", Zeitschrift. wiss. Theolog., 34, 1891, págs. 356-367; BEAujou, J., obra citada, pág. 72; FuCHS, H., “Tacitus ürber die Christen», Vigiliae Christianae, 4, 1950, págs. 65-93; FREUNDERBERGER, R., “Der Vorwurf ritueller Verbrechen", Theolog. Zeitschr., 23, 1967, págs. 97-107; WALTINZ, J. P., “Le crime rituel reproché aux chrétiens du $\|^{\text {eme }}$ siècle", Musée Belge, 29, 1925, págs. 209-238. Sobre las persecuciones contra los cristianos y sus posibles motivaciones, ver tambien: Roos, A. G., Nero and the christians. Symbolae ad ius et historiam antiquitatis pertinentes. I. Chr. van Oven dedicatae, ed. M. David, B. A. van Groningen and S. M. Meijers, Leiden, 1946 pág. 302; MoMigliANo, A., "Nero", Cambridge Ancient History, cp. XXI, Cambridge, 1934, pág. 887; MOREAU, J., La persécution du christianisme dans l'Empire Romain, París, 1956; GRIFFE, E., Les persécutions contre les chrétiens aux $1^{\mathrm{e}}$ et $\mid \mathrm{II}^{\mathrm{e}}$ siècle, Paris, 1967, págs. 37 y ss.

${ }^{22}$ Principe Augusto nomen hoc ortum est; Tiberio disciplina eius iluxit; sub Nerone, damnatio invaluit ...Permansit. erasis omnibus, hoc solum institutum neronianum. 
que la primitiva comunidad cristiana fue acusada y perseguida por delitos contemplados por el Derecho común romano, no siendo necesaria una ley especial contra los mismos (Borleffs, J. W. Ph., 1951; Saumagne, Ch., 1961). Tanto si los cristianos fueron acusados de incendiarios como de practicar una execrable superstitio, estaban previstas las leyes con sus correspondientes penas y condenas a tales delitos:

- La Lex Julia de vi publica (sobre la violencia pública), que podía ser aplicada en caso de atropello, tumulto o incendio (qui coetu conventu turba seditioni incendium fecerit).

La pena era capital y su ejecución podría ser la más severa, si se aplicaba además la ley Cornelia de sicariis, es decir, crucificados e incluso quemados (Marciano, Dig., 48, 6, 5; Paulo, Dig., 48, 6, 9, y Sent., 5).

- La Lex lulia Maiestatis (sobre la majestad), que reprimia todo atentado contra el Estado, la divinidad de los césares y las divinidades protectoras del pueblo romano. Todo acto considerado delictivo por su comportamiento o por pertenecer o constituir reuniones ilícitas cuyas actividades se consideraban peligrosas para la libertad pública, la decencia moral o la neutralidad política se consideraban delitos públicos y eran castigados como tales por esta ley común romana: Crimen illud quod adversus populum romanum vel adversus securitatem committetur (UIpiano, Dig., 48, 4-11).

En el siglo I, bajo Tiberio, Nerón y Domiciano, una jurisprudencia más completa y extensiva englobaba también: "Todo atentado y toda apariencia de atentado a la grandeza y dignidad del pueblo romano". Tales "apariencias" pasaban a ser automáticamente delitos de Lessa maiestas (Tácito, Ann., I, 72, y XV, 44).

Sin duda, la comunidad cristiana era ilegal y sus reuniones y la práctica de su religión ilícita, y por tanto delictiva. Tanto a causa de esta ilegalidad como los "crimenes secretos" (in occulto), así denominados por el propio Tertuliano, sus miembros estaban sujetos a ser condenados por esta ley como hostes publici y convicti odio humani generis, según la propia fórmula de su vocabulario jurídico, recogida en el famoso texto de Tácito (Callewaert, C., 1911, 5-16; Crake, J. E. A., 1965, 61-70; Barnes, T. D., $1968,32-50)^{23}$.

${ }^{23}$ También se ha pensado en la posibilidad que la comunidad cristiana perteneciera a uno de tantos Collegia illicita, o corporaciones no reconocidas por la autoridad romana. Respecto a ello, De Rossi, G. B., emitió la hipótesis que los cristianos primitivos debieron 
Ante el análisis de estas leyes, es evidente que el gobierno neroniano no tuvo mas que acudir a la legislación vigente y seguir los procedimientos existentes de la maquinaria judicial romana.

Así cuando Tácito indica que Nerón subdidit reos no hace sino someter a procedirnientos legales (leges publicae) a posibles sospechosos de delitos castigados en el Derecho común (como sacrilegi, hostes publici y maiestatis rei).

"Los condenados merecieron la pena suprema siguiendo las ejecuciones formales y aceptadas por Nerón, que por su enorme e inútil crueldad provocaron la conmiseración popular" (Tacito, Ann., XV, 44) ${ }^{24}$.

Por otra parte, carecemos de cualquier tipo de testimonio que confirme la existencia de una ley o decreto imperial promulgado específicamente contra los cristianos en época neroniana.

También parece contradictorio que tras la muerte del último JulioClaudio, abolidas con su memoria todas las medidas tomadas por Nerón por orden del Senado, ésta, precisamente, fuera mantenida, subsistiendo prácticamente hasta la dinastía severa, a no ser que ésta se considerara no sólo justa sino necesaria.

Se ha mantenido, sin alegar pruebas suficientes, que la palabra Institutum sería equivalente en su utilización a la palabra "Lex» en el texto de Tertuliano: Et tamen mansit erasis omnibus hoc solum Institutum Neronianum, iustum denique ut dissimile sui auctoris (Tertuliano, Ad Nat., I, 7-9) ${ }^{25}$.

Sin embargo, el análisis del conjunto del texto de Tertuliano no parece corroborar esta opinión.

En primer lugar, el sustantivo Institutum no parece tener ninguna propiedad técnica que lo acredite. Esta palabra con carácter legal es escasisimamente empleada y solamente se hace cuando se refiere a

legalizar su posición utilizando la forma de colegio funerario; a través de esta forma jurídica podrian incluso adquirir bienes muebles, hipótesis que no ha sido confirmada: DE Rossı, G. B., Roma sotterranea, I, pág. 101, III, pág. 507; Ibídem, en Bull. di Archeol. crist., 1864, págs. 57 y 1865 , pág. 40 .

${ }^{24}$ Es muy significativa la desigual conducta de Nerón ante las victimas del célebre proceso de L. Pedanio Secundo, por la que el César llegó a sentir clemencia ante la intransigencia de la aristocracia senatorial, y el excesivo rigor demostrado contra los cristianos. Es posible que las circunstancias en Roma obligaran a una aplicación diferente de la justicia.

${ }^{25}$ De este texto se realizó la lectura cristiana posterior: LACTANCIO, De mot, persec., 3 , 1; Eusebio, Hist. Eccles., III, 17 y 20, 7, C. Litt Petiliani, II, 202. 
casos muy concretos y singulares, que en nada se relacionan con el texto de Tertuliano.

En efecto, los Instituta son ciertamente tradiciones constantes que hacen que una familia se someta hereditariamente (morum sourum instituta); o bien, reglas domésticas relativas al nivel de vida alcanzado por un individuo; si éste se trata de un cliente debe ser respetado por su patrón, el cual no podrá imponerle ciertas obligaciones ni trabajos: operae quibus institutum vel propositum vitae minuitur ${ }^{26}$.

No se encuentra otra significación legal del término Instituta, aunque éste aparece tras una serie de disposiciones dadas en conjunto por $\mathrm{Ne}$ rón en el texto de Suetonio, del que, muy probablemente, ha sido tomado por Tertuliano: Multa sub eo (Nerone) et animadversa severe et, coercita, nec minus instituta. A continuación Suetonio enumera seis iniciativas consideradas como beneficiosas logradas por el césar, sin que exista relación aparente entre las mismas, una de ellas es la disposición de persecución a los cristianos (Suetonio, Nero, 16).

Ch. Saumagne ha considerado acertadamente que tal palabra no se trata sino de un participio de pretérito (Instituta sunt), lo cual estaría acorde con el estilo conciso del autor de la Vita Caesarum; de este pretérito de Suetonio, instituta, en plural, fue transformado en la obra de Tertuliano en un sustantivo singular, al referirse solamente a la disposición contra los cristianos y muy posiblemente sin intención de modificar su significación intrínseca y gramatical. Sin embargo, ésta ha sido tradicionalmente interpretada con impropiedad terminológica, llegando a traducir el término Institutum como Decretum o Edictum, y así fue introducido en la Historia, error explicable y excusable, que ha modificado, en cierto modo, el proceso de la persecución a la comunidad cristiana desde sus orígenes (Saumagne, Ch., 1961).

El incendio de Roma del año 64 llevó consigo importantes y significativas consecuencias que fueron determinantes en la historia posterior de Roma.

${ }^{26}$ Cfr. R. Cicerón, In Pisonem, 30; Seneca, Epis., 86, 2; TÁito, Ann, XIV, 43, 1; Apuleyo, De mundo, 31; Anonymus, Declamatio in L. Serg. Catilinam, 4 y 64 . La diferencia entre estas palabras se encuentra con claridad en Justiniano, Inst., I, 2-10: Origo eius (sc. iuris civilis) ab institutis duarum civitatium. Athenarum scilicet et Lacedaemoniorum, fluxisse videtur: in his enim civitatibus ita agi solitum erat, ut Lacedaemonii quidem magis ea, quae pro legibus observarent, memoriae mandarent. Athenienses vero ea, quae in legibus scripta reprehendissent, custodiarent. 
Muy posiblemente tuvo un origen accidental, como tantos otros anteriores, no sólo en Roma, sino en otras ciudades de la Antigüedad, pero debido a sus catastróficas dimensiones y la difícil situación que atravesaba el Imperio hizo que el incendio alcanzara ciertas connotaciones sociales y políticas. Fue aprovechado por sectores contestatarios contra la política imperial, y tal vez por el propio gobierno para acabar con las minorias confesionales no gratas ni a la sociedad ni al gobierno romano: judíos, cristianos, estoicos u otros oscuros pietitas, mal vistos por la sociedad y contra quienes se lanzó la animosidad popular.

No es probable que podamos llegar a saber con certeza hasta qué punto Nerón castigó a los cristianos por su propia voluntad o fuese obligado por necesidades políticas y por la propia exigencia popular. Si parece seguro que éstos fueron acusados y procesados como incendiarios o como enemigos públicos por las vías normales de la justicia romana.

Es posible que con Nerón se iniciara el origen y la base jurídica de las persecuciones que más adelante tomara el sentido de costumbre y de uso, institucionalizándose. 


\section{BIBLIOGRAFIA}

BARNES, T. D., "Legislation against the Christians", The Journal of Roman Studies, LVIII, 1968, págs. 32-50.

BEAUJOU J., "L'incendie de Rome et les chrétiens", Latomus, 1960, págs. 65-80.

Bonifante, P., Storia del diritto romano, t. II, Milán, 1923.

BorleffS, J. W. Ph., "Institutum Neronianum", Vigiliae Christianae, 5-6, 1951, págs. 129-145.

De Franco, U., L'incirteza di Tacito e la ipotesi recenziori sullincendio Neroniano, Catania, 1956.

Ibídem: L'incendio di Roma e la congiura di Pisone, Catania, 1946.

DE STE. Crolx, G. E. M., "Why were the Christians Persecuted?, Past and Present, 26, 1963, págs. 6-38.

CAllewaert, C., "La méthode dans la recherche de la base juridique des premiers persécutions", Rev. d'Histoire Ecclesiastique, 12, 1911, págs. 5-16 y 633-657.

Clayton, F. W., "Tacitus and Nero's Persecution of the Christians", Classical Quaterly, 41, 1947, págs. 81-85.

Crake, J. E. A., "Early Christianity and Roman Law», Phoenix, 19, 1965, págs. 61-70.

Hermann, L., "Quels chrétiens ont incendié Rome? Rev. belge de Philosophie et d'Histoire, 17, 1949, págs. 633-651.

Koestermann, E., Cornelii Taciti Libri qui supersunt. T. I, ab. Excessu Diui Augusti, "Bibliotheca Teubneriana», Leipzig, 1971; Ibídem, "Ein Folgenschwerer Irrtum des Tacitus (Ann., XV, 44, 2)", Historia, 1967, págs. 45 y ss.

LEPELLEY, C., "L'Empire Romain et le Christianisme", Questions d'Histoire, 12, 1969.

MEEKS, W. A., Los primeros cristianos urbanos, Salamanca, 1985.

NESTLE, W., "Odium humani generis", Klio, 21, 1927, págs. 91 y ss. 
Paratore, E., "Nerone (nel XIX centenario della morte)", Studii Romani, 17, 1969, págs. 272-287.

PASCAL, M., L'Incendio di Roma ed i primi cristiani, Turín, 1900-1; página 8.

Profumo, A., Le fonti e i tempi dellincendio neroniano, Roma, 1905.

SAMPLEY, J. P., "Societas christi: Roman law and Paul's Conception of the Christian Comunity", God's Christ and His People: Studies in Honour of Nils Alstrup Dahl, Oslo, Bergen and Tomsö Universitetsforlaget, págs. 158-74.

Ibídem. Pauline Partnership in Christ: Community and Commitment in Light o Roman Law, Filadelfia Fortress, 1988.

Saumagne, Ch., "Tacite et Saint Paul», Rev. Historique, 232, 1964, págs. 67-110.

Ibídem, "Tertullien et l'Institutum Neronianum», Theologische Zeitschrift, 17, 1961, págs. 334-355.

SherWIN-WHITE, A. N., "Why wer the Christians Persecuted? An Amendment", Past and Present, 27, 1964, págs. 25 y ss.

SCHILlER, H., Geschichte des Römischem Kaiserreichs unter der Regierung des Nero, Berlin, 1872.

SYME, R., Tacitus, Oxford, 1958, t. II.

THEISSEN, G., Estudios de sociologia del cristianismo primitivo, Madrid, 1985.

ZeILLER, L., «Institutum Neronianum. Loi fantôme ou réalitè?», Rev. des Études August., 2, 1956, págs. 257-263.

Ibídem, "Nouvelles remarques sur les persécutions contre les chrétiens aux deux premiers siècles", Miscellanea Giovani Mercati, Studi e Testi, 125, Roma, 1946, V. V., págs. 1-6.

Ibídem, "Nouvelles observations sur l'Origine juridique des persécutions contre les chrétiens aux deux premiers siècles", Rev. d'Histoire Ecclesiastique, Lovaina, 1951, XLVI, págs. 521-533.

ZELLER, E., "Das odium humani generis der Christen", Zeitschrift, wiss Theolog., 34, 1891, págs. 356-367. 